\title{
Science cafés. Cross-cultural adaptation and educational applications
}

\author{
M. Norton and K. Nohara
}

\begin{abstract}
Tokyo Institute of Technology (TokyoTech) has been developing a number of methodologies to teach graduate students the theory and practice of science communication since 2005. One of the tools used is the science café, where students are taught about the background based primarily on theoretical models developed in the UK. They then apply that knowledge and adapt it the Japanese cultural context and plan, execute and review outcomes as part of their course. In this paper we review 4 years of experience in using science cafés in this educational context; we review the background to the students' decision-making and consensus-building process towards deciding on the style and subject to be used, and the value this has in illuminating the cultural influences on the science café design and implementation. We also review the value of the science café as an educational tool and conclude that it has contributed to a number of teaching goals related to both knowledge and the personal skills required to function effectively in an international environment.
\end{abstract}

\section{Background and objectives}

The TokyoTech (Tokyo Institute of Technology) programme "Science and Engineering Communication: Theory and Practice" seeks to cultivate researchers with communication skills and the ability to appreciate science's interaction with Society. The Master's unit is comprised of three segments. The first is a full 15week lecture course (with the normal 2 credits) providing knowledge about science communication and its related theories; the second (also with 2 credits available) provides two options for practical experience in some aspect of science communication. The first option is to take part in internships both inside and outside Japan to obtain practical experience of science communication in museums, public policy institutions, or media organizations. The second option for practical training is based on the science café (café scientifique), where students must plan and execute their own science café. The course and its impact on student's abilities via internship modules have been previously described [1,2].

The second practical option (science café) was selected because this technique has grown in importance as the former theories of science communication (based on 'deficit model' of science communication [3]) have been superseded by the 2-way engagement model [4] which seeks to generate dialogue among equals between scientists and the public [5]. However, most of the theoretical development in science communication theory [6], and initial experience in the development and implementation of science cafés has been outside Japan (especially in the UK [7]). In offering this option in our course, we thus had to consider how this technique developed in Western cultures should be adapted for Japanese use, and how designing and implementing a science café can contribute to educating scientists and engineers to act at the interface between science and society.

This paper thus looks at the factors we considered in designing a science café process for use in an educational (practical training) role, and the initial results obtained from the first 2 years' implementation. Our focus is on the role of the science café as an educational tool. We thus first consider the evolution of the science café concept and its theoretical development, and the case for cultural adaptation to Japan. We then examine the thinking behind the design of cafés adopted by students in the TokyoTech course and their pedagological implications. Our aim is to provide an evaluation and case study which will allow other educators to judge the potential value of this technique in achieving their own objectives in science communication education. 


\section{Context: Science Café Models and Host Cultures}

The first science café is generally attributed to Leeds Café Scientifique in the UK in 1998 [8]. As a result of that initiative, some 30 cafés have been set up around the UK [9]; the UK is also the base for a well funded initiative at the Dana Centre established in 2003 next to the London Science Museum [10]. The idea has spread to the USA, within Europe, and elsewhere. As far as Japan is concerned, science cafés have grown since their first recognition as a communication tool in the Government's 2004 Science and Technology White Paper [11]. Some are organised by professional societies (such as the Science Council of Japan; others by private foundations (e.g. the Takeda Foundation); others by universities and research institutes as part of their outreach work [8]. With such a range of backgrounds and implementing organisations, this inevitably leads to diversity in aims and methods, which is important to recognise when considering the inclusion of a science café in the educational context.

At the time the first science café was established in the UK, academic debate on the effectiveness of science communication [5] was increasingly focusing on weaknesses in the 'deficit' model of Public Understanding of Science (PUS) which had provided the main theoretical framework for a range of government and professional initiatives since the Royal Society's 'Bodmer report' in 1985 [3]. This had postulated a communication 'gap' between scientists and the public which was perceived to underlie public unease and hostility on a range of science-related issues. This model attributed negative public attitudes to a knowledge 'deficit', and led to extensive PUS programmes to communicate science and emphasise its key role in society.

During the PUS era however scientific controversies, far from subsiding, grew in intensity typified by issues such as BSE, radioactive waste and GMOs. The 'one way'communication thinking underlying the deficit model was challenged by the UK House of Lords Science and Technology Committee [4] in 2000. Public concerns, rather than being founded in ignorance, often reflected broader psychological, social, cultural and institutional factors that shaped public attitudes to scientific advances and technological developments. The Committee concluded that the deficit model needed to be replaced with a 'democratic engagement' model based on an open, transparent and inclusive dialogue with the public. Jackson et al. [6] provide 3 anticipated benefits from such dialogue.

- $\quad$ increasing democracy by promoting open and transparent decision-making

- greater trust and confidence in the regulation of science and the decisions taken

- better decision-making.

The term 'dialogue' is thus linked with the process whereby democracies decide between different futures made possible by science and technology (how 'society' should use science). In dialogue, a lack of scientific knowledge should not prevent citizens from discussing ethical viewpoints, nor questions such as their trust in the regulatory process. It also signifies that scientists should understand Society's moral positions. They are no longer the exclusive holders of 'knowledge' in the PUS model. In line with the new (2-way) dialogue thinking, many 'engagement' projects have been launched in the UK and elsewhere [7], and science cafés are often seen as part of this 'democratic engagement' tool-kit.

This new 'engagement' model implies greater equality in dialogue and less overt motives (to persuade) than in the former PUS model. Nevertheless it would be naive to suggest that engagement protagonists are free of motives. Scientists and scientific institutions may still hope that a more informed public will have greater understanding of and sympathy for, science. Governments and educators may hope that engagement with science may lead to more pupils studying science to deal with a perceived skills shortage in 'knowledge economies'. Others hope it will democratise science by facilitating greater participation in science-related issues. Policy-makers may also hope it will place the policy process on a more reasoned basis and reduce opposition they regard as irrational [5].

It has been claimed [8] that science cafés lack such specific agendas. However, their primary role of helping science move into the public arena and interacting with citizens, nevertheless allows multiple motives and outcomes, depending on the way the interaction is managed. A useful guide to classification is between those which follow the earlier (PUS) model and those which embrace the later dialogue/engagement model. For instance in many US science cafés, the focus seems to be on informing the public about science developments in lay-mans terms. The extensive range of science cafés facilitated by the PBS Nova Science Now organisation describes science cafés as "lively informal conversation about a scientific topic" [12]. Another cafe describes its mission as "The Science Café is a place at the intersection of science and life where scholars mix and mingle with the like-minded" [13]. This type is often structured 
around the 'let's ask an expert' model aimed at informing the audience. In contrast, many UK science cafés typified by the Dana Centre explore controversies from both scientific and non-scientific viewpoints with considerable care taken to place both 'experts' and 'non-experts' on an equal footing [14].

What role may the host society's attitude to the status of knowledge holders and their role in society decision-making have to play in the style of science cafés? Americans have more positive attitudes to science and technology and its benefits than Europeans at all levels of scientific literacy [15], which may encourage the 'knowledge transfer' style cafés above. In the period during which the number of science cafés has grown, the US has also seen a marked trend towards the politicisation of science whereby science is (mis)used as a tool or weapon in a basically politically driven debate (e.g. [16,17]), instead of seeking to resolve science-based controversies through rational evidence-based policy analysis. This tendency may lead to a wish to avoid controversial issues because of the difficulty of isolating the controversy as a scientific issue separate from potentially divisive political dimensions. In contrast, in the UK, engagement has been seen as a means of integrating value and other belief systems of the public into the decision-making process on scientific issues through upstream dialogue [6,7]; here there is an presumption that the 'expert', far from being the dominant player, has to adapt to the broader societal constraints arising from society's value and belief systems.

Science cafés evolved in the UK as a methodology for implementing 2-way engagement with the public on issues concerning science and technology, and as such can trace their theoretical foundation to the seminal report by the House of Lords [4] on Science and Society. This was triggered by widespread public unease on key issues such as genetically-modifed organisms, nuclear power, Bovine Spongiform Encephalopathy (BSE) and many other issues. Common underlying themes to such issues included the scientific treatment of risk, and how ethical values should be taken account of in the research or regulatory process (e.g. human embryo research). This 'social framework' perhaps explains why UK science cafés such as the Dana Centre actively seek controversial issues around which to generate their dialogue [10].

Compared with the situation in Europe, surveys suggest that the Japanese public too has concerns over science and technological issues. On the subject of acceptance of GMO foods, the 2005 Eurobarometer survey [18] found that $21-32 \%$ of Europeans (spread of four age ranges) totally agreed or tended to agree with GMO foods, and 54-61\% totally disagreed or tended to disagree. In a 2002 comparative survey [19], Japanese respondents, in answering the question "How willing are you to consume foods with GM ingredients?" $83 \%$ said they would avoid or were not very willing to consume GMO foods (compared with only $18 \%$ in the USA and $56 \%$ in Norway). The public also appears willing in principle to participate in engagement. In a survey on the relations of Science and Technology to Society (February 2004 [11]), 69.7\% agreed to some extent with the proposition that "In the future, the development of science and technology is expected to have stronger impacts on the lives of citizens. The formation of policies pertaining to science and technology will increasingly require the involvement not only of specialists such as researchers and administrative officers, but also citizens".

Such data suggest that the Japanese social framework is favorable to the concept of engagement, and this has been reflected in the rapid growth of science cafés in Japan referred to earlier. Such events are normally held by organizations, such as universities, corporations, research institutes and NPOs, which are motivated to promote interest in and understanding of science among the general public. The targets, formats and venues for such events vary, but since their introduction has been relatively recent, they have been able to benefit from the prior learning and experience of the original concept imported from the UK. This has then been adapted to Japanese culture and needs; and further adjusted in accordance with the organisers' various formats and objectives. Some diversity has thus already evolved towards a 'Japanese' model or style; e.g., a group that discusses science in a pub-like atmosphere as if it is an extension of their normal lives [20], a café created as a local event aimed for cultivating a sense of community [21], a café with a stylish and intelligent image that also contributes to connecting participants with science [22]. The Takeda Foundation is one of the most active NPOs in pursuing science cafés and since 2005 has held over 20, covering subjects from mathematics to brain function [21]. Recently such cafés have emphasised their interest in generating controversy by labelling the series as "views of the child of heresy (Itanji no miru seimei). This characterises the viewpoints put forward by key speakers as out of the mainstream as one way to stimulate interest (e.g. co-existence with microbes, life in space). 


\section{Adapting Theory and Practice to the Design of the TokyoTech Science Cafés}

\subsection{The Design Process}

Students who participate in the course "Science and Engineering Communication", plan and organise a science café as described in Section 1. The students are solely responsible for selection of themes and speakers, structure of the proceeding, and the design of the place of meeting. The meeting is held either once or twice per year, depending on the number of participating students. Themes selected are in table 1.

The students have the generally accepted significance, possible formats, and history of science cafés as a part of their knowledge acquired through the lectures provided in the course. Based on that knowledge, they create the image and design of the café freely on their own. Since it is a part of the second semester (of the Japanese academic year) curriculum, they plan and execute the project during the five months from October to February, but in reality the amount of time available is limited by the demands of lectures and their own research studies. Consequently, much of the preparatory work is through the exchange of ideas via a mailing list. The volume of their mail exchanges is large, and gets particularly heavy towards the end of the preparation. The teaching staff try to maintain the students' focus on their objective by watching the discussions in real time (especially on aspects such as soliciting professionals' cooperation, securing a meeting place, general scheduling), and occasionally correct them and provide optional ideas. Despite this input, it is the students who debate and develop the concept of their own science café. They tend to focus on two criteria: "what type of café event Japanese participants (especially the target group) are likely to enjoy" and "what type of café event they themselves, as young scientists and engineers, can deliver effectively". They are fully aware that it is not easy to achieve an active discussion with strangers on a scientific issue, especially in a country where specialists' opinion is traditionally respected and uncontested (next section). What they come up with at the end of their preparation is a practical model of a 'science cafe' which they believe suits the Japanese public and achieves their own expectations.

\begin{tabular}{|c|c|c|c|}
\hline & Topic \& Targeted Participants & Participants & Place \\
\hline 2005 & $\begin{array}{l}\text { Future energy and electricity } \\
\text { General public }\end{array}$ & 30 & $\begin{array}{l}\text { Miraikan } \\
\text { (science museum) }\end{array}$ \\
\hline 2005 & $\begin{array}{l}\text { Eye tiredness and computing } \\
\text { General public }\end{array}$ & 25 & TokyoTech campus \\
\hline 2006 & $\begin{array}{l}\text { Rocket- fighting gravity } \\
\text { High-school students }\end{array}$ & 15 & TokyoTech campus \\
\hline 2006 & $\begin{array}{l}\text { Solar cells \& fuel cells } \\
\text { General public }\end{array}$ & 20 & TokyoTech campus \\
\hline 2007 & $\begin{array}{l}\text { Taste } \\
\quad \text { General public }\end{array}$ & 12 & Coffee shop \\
\hline 2008 & $\begin{array}{l}\text { Overcooling } \\
\text { General public }\end{array}$ & 31 & Local pub \\
\hline
\end{tabular}

Table 1. Science Cafés Held 2005-8.

Audience composition was monitored at each café and a questionnaire issued to determine age and profession. Gender balance was 50:50 in the 2007 and 2008 cafés. In contrast, the 2005-2006 cafés (apart from the one for high-school students) showed more male dominance. We attribute the high female attendance in 2007 to the topic selected (the human mechanism of feeling sweet/sour) and the popular title used ("Science Parfait"); while in the case of the 2008 event, this seemed to have attracted many of the regular pub customers. Participants in the two recent events also exhibited more diversity in age from teenagers to late $60 \mathrm{~s}$, and in professions (engineer, journalist, student, office clerk, housewife, retired etc.). Without such special factors, we observed that a science café tends to receive more male attendants in their 30s-60s whose work is related (however remotely) to science or technology. However our later experience is reassuring in that it appears possible to attract more attention from females, youngsters and people with a variety of jobs by selecting an appealing topic carefully and putting more effort into publicity. 


\subsection{Engaging the Audience and 'Dialogue'}

The Course emphasises the starting points for science café as a means of promoting dialogue - the process by which opinions, ideas and information are shared between two or more parties; moreover dialogue involves a presumption of equality, so that information and opinion based on a citizen's own belief system should be treated with the same respect as that based on professional expertise. For instance, the Dana Centre has developed a theoretical model for encouraging and measuring dialogue [14] in the context of developing its own model, in which the role of facilitator is important. The degree of success in delivering dialogue can also be measured by recording who asked how many questions, what comments were made from what position/location in the room, and analysed for insights which can improve the degree of dialogue.

Some of these aspects transfer readily to Japanese culture because of its tradition of respect for other individuals' opinions and avoidance of direct challenge and conflict. However this culture of respect towards teachers, doctors and other professional groups has the associated weakness (from the science café point of view) of their knowledge being accepted without scepticism or questioning. To adapt to such cultural realities, the Takeda Foundation science cafés use a facilitator who leads the discussion in a subtle way [21]. Although participants are actively voicing their opinions, they adapt their thinking towards the issues the facilitator provides, so that opinions can be steered to match the topic, and the discussion not derail from the prepared scenario. In other words, it is possible to have a 'pseudo debate' of a Japanese kind, where there is a scenario prepared to a degree, and guided by 'authorities'. Even under such a format (in other words, where discussions are not quite of the autonomous and spontaneous kind which develop into full engagement), participants can still have some sense of achievement as a result of voicing their opinions and sharing a scientific theme and information. The TokyoTech Science Café uses a similar approach in providing a leader figure, but since this is being planned by the students there is a presumption that this figure should be one of them. To make it easier to guide, they prefer to include experiments and/or demonstrations in the event, or to make use of performance factors as a means of communicating information to the participants from the organisers (see section 4 ).

\subsection{Café Participants}

The general motive of science cafés is to involve the general public, but what kind of public? The 2002 survey on public attitudes towards scientific developments in the UK [23] proposed the six attitudinal groups in table 2, rated according to their attitude to the role of S\&T in Society, the ability of government to control science, trust in scientists, ability to cope with change, level of interest and appetite for more information.

\begin{tabular}{|c|c|c|c|c|c|c|c|}
\hline \multirow[t]{2}{*}{ Category } & \multirow[t]{2}{*}{ Proportion } & \multicolumn{5}{|c|}{ Key characteristics: } & \multirow{2}{*}{$\begin{array}{l}\text { Interest in } \\
\text { more science } \\
\text { information }\end{array}$} \\
\hline & & 1 & 2 & & 4 & 5 & \\
\hline Confident believer & 17 & +++ & +++ & + & +++ & +++ & + \\
\hline Technophiles & 20 & +++ & ++ & ++ & ++ & +++ & + \\
\hline Supporters & 17 & ++ & ++ & + & +++ & ++ & + \\
\hline Concerned & 13 & -- & -- & - & ++ & ++ & ++ \\
\hline Not sure & 17 & - & + & + & + & -- & - \\
\hline Not for me & 15 & + & + & + & - & - & - \\
\hline $\begin{array}{ll}\text { 1. } & \text { Role of S\& } \\
\text { 2. } & \text { Ability of } \\
\text { 3. } & \text { Trust in Sc } \\
\text { 4. Ability to } \\
\text { 5. Level of In } \\
\text { High }+++++\end{array}$ & $\begin{array}{l}\text { ty } \\
\text { change } \\
\text { w }\end{array}$ & & & & & & \\
\hline
\end{tabular}

Table 2. Attitudinal Groups in UK Survey (23).

Different designs of science café will attract different audiences. In the case of the PUS model, it may be the "like-minded individuals who can discuss how science enriches their lives" [13]. Such a model is likely to be attractive to 'technophiles' and 'supporters'; 'Concerned' who attend to raise their concerns 
may not feel welcome. On the other hand the Dana model actively seeks to engage those who are focused on the issues as well as those who would normally never consider an event based on science- the "Not sure' and 'Not for me' groups, with a particular focus on adults in the age range 18-45.

In considering the target participants for the TokyoTech Science Café, the students considered:

- The likelihood of attracting an audience

- The likelihood that attendees will participate once they were there

- The likelihood that participants will receive positive impressions on science through the event.

There points are reflected in the decisions TokyoTech students make in selecting the subject (table 1). Although numbers are too low to support detailed audience profiling, the audiences have all decided themselves to attend based on limited publicity which suggests a dominance of 'technophiles' and 'supporters'. We have noted that students try to stimulate some interaction between people of different backgrounds. However, they are not yet at the stage of targeting certain categories of people, such as 'confident believers' or "concerned", but more focused on first establishing a reproducible framework which can support casual dialogue on science which is not available elsewhere in Society. Organising an event targeting certain specific groups is something more advanced which may follow progress on addressing controversy (next section).

\subsection{The Role of Controversy in Promoting Dialogue}

A key tool in generating dialogue in science cafés can be controversy; without controversy there may be little motive for some to attend an event or once there, contribute [14,24]. Brante et al. [25] differentiate between Science-fact and Science-based controversies. Science-fact controversies arise where knowledge is still developing so that there is ample room for multiple and competing interpretations. For example, the degree of genetic contribution to common diseases, the interaction of diet and health, health effects of drug use, effects on behaviour of screen violence, are all areas of contention within the expert community and thus 'Science-fact' controversies. In contrast, a Science-based controversy focuses on the implications and consequences of scientific knowledge for society -risks, ethics, costs, political response etc. The latter focuses on interactions between scientific and non-scientific knowledge (personal beliefs, individual experience and opinion), and can be more accessible to the non-expert citizen. For instance, societal responses to climate change, drug abuse, nuclear energy etc.

This differentiation also gives us a basis on which to define the purposes of individual science cafés. We can consider a spectrum from one way PUS, through Science-fact controversies through to science issue controversies involving 2-way engagement.

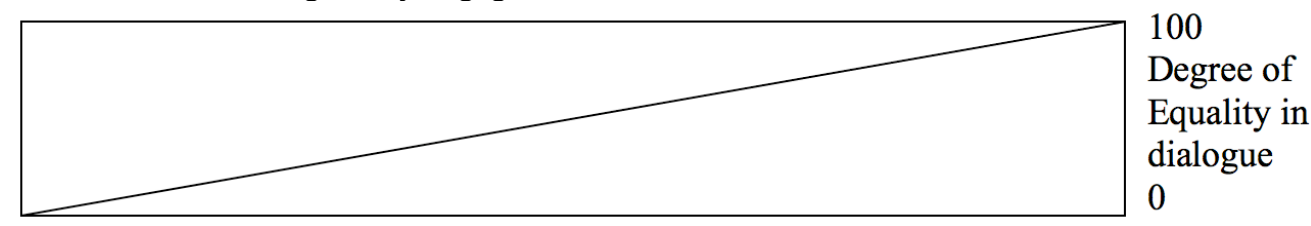

PUS (1-way)
Education
Science-fact
Informed discussion
Science-based issue

debate on values etc

Figure 1. A model of Science Café type and Dialogue Depth.

For instance, the New York science café programme for December 2007 looked at "how red wine helps the heart and other chemical mysteries" [26]. This is PUS. The Southern California science café event for July 2007 was "global warming; the facts" [13]. This subject has emerging science and therefore the potential for Science-fact controversy. However, since there was only one speaker, this may have tended towards PUS. A model of having experts with different viewpoints would be conducive to a Science-fact controversy. Here the audience can enjoy, participate, and be informed by the debate, but is unlikely to possess scientific knowledge which will materially influence the outcome of the 'Science-fact' debate.

In contrast, the Science-based controversy favoured by the science cafés typified by the Dana Centre (such as the extent to which personal behaviour change can influence global warming, ethical implications of stem cell research, whether drugs in sport are fair-27) helps participants to contribute on 
an equal footing by focusing on the societal implications of scientific development, where ethical, moral and personal judgements are an essential part of the controversy. Such questions place the lay participants on a more equal footing with the experts.

Dialogue based on controversy may pose particular challenges in Japan, since it is often pointed out that Japanese may be reluctant to verbalise personal opinions, and especially reluctant to advocate these in a controversial context. It is said that this is due to a lack of instruction in schools on how to express one's opinion and how to pursue a discussion with other people, and also that it is considered improper in social manners to press one's opinion forward against the general trend of the group. For these reasons, we judged that it would be difficult to create a science café based only on controversy and also difficult to create an environment for a free and spontaneous discussion.

The result is (table 1) that the subjects chosen by the students with some advice from the teaching staff have steered away from controversy. There have been mainly three criteria for subject selection: 1) whether the students think the subject is attractive enough for a group of ordinary people to attend; 2) whether they obtain an appropriate speaker or specialist to the event, 3) whether they believe the event will produce satisfaction and a positive feeling towards science among the participants. The last point has attracted a high priority because one of the main course lectures is given by a TV science programme producer, and he provides a 'professional' comment on the students' plan and its 'presentability'.

While the students have tended not to choose Science-based controversies which could trigger substantial debates on ethical or moral issues between experts and lay people, they did hold cafés on future energy (2005 and 2007), which had the potential for such an approach. However, they did not choose to lead or promote the event in the direction of active discussion on moral topics so that it remained dominantly scientific and factual. This suggests that in practice the TokyoTech Science Café has positioned itself in the territory around PUS education and Science-fact controversy in figure 1.

However, as the degree of interaction between science and society grows - especially in the field of issues related to sustainability, we anticipate a greater willingness to embrace science-issue controversies and thus see a need to educate with this in mind. This should provide support for the students' science café to develop in this direction once they recognise the significance. Training is thus being provided in identifying suitable subjects and the qualities which contribute to controversy: for instance

- Many controversies are related to risk, perception of risk or debate over who should accept the risk.

- Controversies are often time-limited, and therefore topicality is a key factor. This means that students need to develop an ability to scan the media for potential topics.

- Ethics and moral values often feature, so that students may require training in identifying different groups who have different senses of right or wrong on that issue.

- Finally, controversy is particularly intense where it affects individuals differently. Thus if the controversy's personal and social relevance can be emphasised this may help motivate contributions to the debate.

\section{Pedagological Results and Insights}

The previous sections have set the development of the TokyoTech Science Café against an historical and international background. Now we wish to comment on the science café as an educational tool and the effects we have noted on the participating students. Our research group consists of four members of academic staff who are involved in science communication studies and education at TokyoTech, occasionally with some temporary members of staff. Each is originally from a different academic discipline: translation studies (including intralingual and intersemiotic translation), linguistics, chemistry and biology. In observing and analysing students' activities in science communication, each researcher uses his/her own methods and perspectives, for example, discourse analysis and contrastive text analysis for looking at recorded and transcribed interviews. The main source of data and materials for evaluation is the recorded interviews of the students after each event, and the e-mails exchanged during the preparation phase.

As listed in table 1 , the theme and format of the cafés has tended to vary so that it is difficult to develop a general theoretical model for the science café plan. However, from staff observation of students' preparations, as well as our participation in and observations of outside science cafés, we can deduce the following: 
1) The students tend to try to map out a direction, and anticipate what kind of summary or conclusion may result from their discussions at the event;

2) they prefer to include experiments rather than just talks in the event;

3) they prefer to make use of performance factors as a means of communicating information to the participants from the organisers.

The first observation shows that they prefer to develop a vision of the way in which the discussion will develop, with the objective of adhering to that vision if they can. We see some misgivings expressed over what they can predict and achieve (e.g. the significance of the conclusion) through a free and spontaneous discussion, so that they feel obliged to guide the discussion in a certain way as an 'authority of science'. ("I wanted to guide the people to some shared conclusion by the end of the evening but it was impossible. I felt very powerless" - facilitator student after the 2005 electricity café).

The second indicates that students adhere to the presupposition that just 'talking' science would not attract sufficient participants. "We, scientists, are engaged in science because it is interesting to do experiments" (student after the 2007 rocket café). This leads to the third observation that they prefer to present scientific information in forms such as a prepared original video or a skit. These tendencies may reflect the way in which the students see science information as being provided or handled in Japanese society (especially TV). However, students also prefer to communicate with participants by 'playing up' science, because they lack experience and 'rules' for communicating with non-professionals, and are conscious that they are away from their normal environment where communication is between science communities in laboratories or professional conferences. ("We disguised ourselves as various characters [such as "Captain Armstrong the navigator" "Mr Gravity" "school kid" and "Miss Rocket"] and managed to entertain the participants. Apparently some of them went to another science café afterwards and I find it very successful" - student after the 2006 rocket café).

The factor of performance or more specifically stage-acting thus emerges as a strong factor in our analysis of the educational role of science cafés. This obviously helps the students who are not used to interacting with lay people, and the role (medical doctor, spaceman or even mad scientist) seems to have a liberating effect for them. The students are usually conscious that they are shy, not fluent and "not a good communicator in general" (class participant 2006). They say they perform on the stage "in order to give the participants, especially young ones, a good time" (facilitator student after the taste café) and it certainly relaxes the other participants - many of them laugh (or at least jokingly sneer) at their colleagues' performance during the event. Although we need to make more systematic observations on the impact of 'playing up', it appears that this factor contributes to the production of a relaxed atmosphere, and helps prepare the ground for dialogue between individual Japanese who may be unused to public discussion.

As an example of one role play, one science café addressed the theme of taste. A student played the role of a 'Taste Scholar' wearing a white coat and thick glasses to convey the stereotypical 'boffin' image, and explained the mechanism of how a tongue senses tastes such as sweetness and sourness. A leading expert in the research of gustatory sense was present as a guest, so there was no real need to have fake experts. However, the fake doctor skit proved an effective strategy for providing sufficient elementary grounding in the science and creating a relaxed atmosphere, from which the debate could then proceed with the involvement of the 'true' professional. This approach had been modelled on the use by the DANA Centre of professional comedians and performers to present information and create a relaxed and entertaining atmosphere - tacit knowledge acquired as a result of certain students' participation in the international internship scheme [1].

However, this approach starts by dividing the participants into a 'stage' of those who 'know' and a 'floor' of those who don't 'know' about the science. This distinction appeared to be preserved in the minds of the participants for the rest of the event as characterised by the audience's adherence to 'ask an expert' behaviour rather than contributing as equals based on their own personal taste experiences or opinions. Based on the observations of the students at the DANA Centre, this was unanticipated since the 'ice-breaking' was expected to encourage a reduction in inhibitions towards full engagement. This raises the question of whether we could have taken preventative measures to avoid such a divide between science professionals and general participants to reflect a possible difference in reactions to performancelike presentations in Japan? It will be important to analyse more cases to evaluate positive and negative effects of delivering information through performance-like presentations, and whether this can be refined 
to reduce the barriers between professionals and the general public, and encourage a mind-set of shared participation and responsibility between constituent elements of society.

As pointed out earlier, students are conscious of the hesitancy in Japan to express one's opinion assertively, and relate it to the meeting context. In addition there are the social pressures not to be a 'nail that sticks out' by pressing one's own opinion forward in a group. However, in the context of preparing students to work in international companies and markets, it is essential be able to discuss various subjects objectively with people of various nationalities, using skills and communication techniques which are competitive- even though this may conflict with social customs in Japan. To this end, we started a Science and Culture Café in English in 2007 with the aim of attracting a broader range of participants, contributing to the Japanese students' abilities to communicate in English, and also encourage certain types of discussions that are not possible in Japanese with its indirect structures.

This allowed foreign students whose English was better than their Japanese to join the mail discussions in English, and thus mail exchanges tended to became bilingual, which was beneficial to the Japanese students from a language educational point of view. Broadening the cultural spread of participation also helped students to recognise the importance of encouraging debate and communication based on objective needs rather than social norms. In particular, they have come to see the purpose of the science café as being to deliver richer wisdoms thorough the sharing of science between professionals and the general public, where poor discussion capability is clearly a block.

With regard to the earlier separation of science cafés according to their degree of equality in dialogue (figure 1), we note from the cumulative experience of developing and applying the TokyoTech Science Cafés that awareness of the significance of shared scientific information between professionals and the general public is accelerating and spreading. However, encouraging unguided and free discussions on an equal standing between professionals and non-professionals, whereby an awareness of science's societal implications are explored in a wide variety of values and contexts, is still unusual. A science café where someone guides the discussion in a way which is more familiar to Japanese is still preferred by the students; as well as role-play style methods to relax themselves. These methods can also serve to create an atmosphere for free discussion, but the supplementary mechanisms required to generate a fully productive debate (engagement) remain to be developed.

\section{Conclusion}

The current 'Japanese style science cafe' can create a feeling of satisfaction and a sense of accomplishment (students and local participants 2007), in which a sense of togetherness emerges through sharing topics and having voices heard. However, for the next step, we should explore the possibility of enabling discussions towards a real engagement model and heighten an awareness of science through exchanging new opinions and thinking. For that reason, participants need to have capabilities to conduct flexible communications that can evolve into a new level beyond presentations and performances, and we believe it is desirable for the educators to help the students to acquire such capabilities through guidance on the planning and execution of future science cafés aimed at this more challenging objective.

\section{Notes and references}

[1] K. Nohara, M. Norton, M. Saijo and O. Kusakabe (2008), Overseas Internships as a Vehicle for Cultivating Meta-consciousness regarding communication, Journal of Science Communication 7(1): 1-12.

[2] O. Kusakabe, K. Nohara, M. Saijo and A. Higashii (2006), The Role of internships based on industry-public sector university collaboration, Kogaku kogyo kyoikukenkyu koenronbunshu, Japanese Society for Engineering Education, pg. 258-259.

[3] Royal Society of London (1985), The Public Understanding of Science, London.

[4] House of Lords Committee on Science and Technology (2000), Science and Society, $3^{\text {rd }}$ report, London, HMSO.

[5] M. Bauer, N. Allum and S. Miller (2007), What can we learn from 25-years of PUS Research? Liberating and Widening the Agenda, Public Understanding of Science 16: 79-95. 
[6] R. Jackson, F. Barbagallo and H. Haste (2005), Strengths of Public Dialogue on Science-related Issues, Critical Review of International Social and Political Philosophy 8(3): 349-358.

[7] M. Norton, K. Nohara and M. Saito (2009), Science Communication history and development- UK and other EU countries' history and approach, pg. 111-126, in Introduction to Science and Technology Communication, Baifukan Publishers, Japan.

[8] Café Scientifique Organisers Conference, Leeds (2007) http://www.muskegoncafescientifique.com/downloads/conferencereport.pdf.

[9] http://www.cafescientifique.org/index.html.

[10] http://www.danacentre.org.uk/.

[11] MEXT (2004), How should Science and Technology comunicate with Society?, Chapter 3, White Paper on Science and Technology, pg. 34-53

http://www.mext.go.jp/english/news/2004/10/04111001/004.pdf.

[12] http://www.pbs.org/wgbh/nova/sciencenow/involved/scientists.html.

[13] http://www.socal-sciencecafe.org/about.htm.

[14] E. McCallie, E. Simonsson, B. Gammon, K. Nilsson, J.L. Lehr and S. Davies (2007), Learning to Generate Dialogue: Theory, practice, and evaluation, Museums and Social Issues 2(2): 165.

[15] NSF (2004). "Public Attitudes and Understanding", Chapter 7 in Science Indicators, Washington, NSF (http://www.nsf.gov/statistics/seind04/c7/c7i.htm)

[16] Lahsen, M. (2005). "Technocracy, Democracy, and U.S. Climate Politics: The Need for Demarcations", Technology \& Human Values, 30 (1), p. 137-169.

[17] M. Norton, N. Allum and G. Kass (2007), Combating Spurious Science, Science and Public Affairs, Dec 2007, p18.

[18] G. Gaskell et al. (2006), Europeans and Biotechnology in 2005: Patterns and Trends, Report to the European Commission's Directorate-General for Research, 113pp http://ec.europa.eu/research/press/2006/pdf/pr1906_eb_64_3_final_report-may2006_en.pdf

[19] W. Chern and K. Rickertsen (2002), Consumer Acceptance of GMO: Survey Results from Japan, Norway, Taiwan, and the United States, Ohio State University, Working Paper: AEDE-WP-002602 , http://www-agecon.ag.ohio-state.edu/resources/docs/pdf/5FE4959A-C1D0-44E7-8DC93811C5418C25.pdf.

[20] http://www.mitaka-univ.org/users/aspub-top.html.

[21] http://www.takeda-foundation.jp/cafe2005/.

[22] http://cafesci-portal.seesaa.net/.

[23] OST and Wellcome Trust (2000), Science and the Public-A Review of Science Communication and Public Attitudes to Science in Britain, Wellcome Trust, London

http://www.wellcome.ac.uk/stellent/groups/corporatesite/@msh_peda/documents/web_document/wtd003419.pdf.

[24] Science Museum Visitors Research Group (2004), Naked Science-Evaluation of 18 months of Contemporary science dialogue events, http://www.danacentre.org.uk/documents/pdf/front-end_evaluation_report.pdf.

[25] T. Brante, S. Fuller and W. Lynch (1993), Controversial Science: From content to contention, Albany, State University of New York Press.

[26] New York Academy of Sciences Café Scientifique http://www.nyas.org/snc/calendarDetail.aspeventID=11010\&date=12/3/2007\%207:30:00\%20PM.

[27] http://www.danacentre.org.uk/aboutus/eventdiy/controversy.

\begin{abstract}
Authors
Mike Norton is Professor at the Innovation Management Institute, Shinshu University, with a $\mathrm{PhD}$ in Chemistry from Bristol University. He worked for the UK Government on environmental protection and biotechnology research and policy (1974-1989). He was Director of the UK Parliamentary Office of Science and Technology where he participated in a number of UK public engagement projects (19891998) and was Counsellor in Science and Technology for the British Embassy in Tokyo from 1998-2004. E-mail: norton@im.shinshu-u.ac.jp
\end{abstract}

Kayoko Nohara received her D. Phil in Translation Studies from University of Oxford. She worked in the Faculty of Oriental Studies at University of Oxford, Gakushuin University, Japan, Katholieke 
Universiteit Leuven, Belgium, and is currently an Associate Professor at Tokyo Institute of Technology, teaching Linguistics, Japanese and Science Communication, and recently leading a new research project in science and art in Japan. Recent publications include: An Introduction to Science and Engineering Communication (Kagakugijutsu Communication Nyumon), eds. M. Kaji, M. Saijo and K. Nohara, Baifukan: Tokyo, 2009. E-mail: knohara@ryu.titech.ac.jp.

How TO CITE: M. Norton and K. Nohara, Science cafés. Cross-cultural adaptation and educational applications, Jcom 08(04) (2009) A01. 